\title{
Calibration of an historic masonry building using measured temperature and heat flux data
}

\author{
Michael Gutland $^{1}$, Scott Bucking ${ }^{1}$, Mario Santana Quintero ${ }^{1}$ \\ ${ }^{1}$ Carleton University, Ottawa, Canada
}

\begin{abstract}
This paper describes a methodology for utilizing building energy modelling software to calibrate against measured ambient and interstitial temperatures and heat flux data for the heritage designated Southwest Tower in Ottawa, Canada. The tower can be described as 'semiconditioned' with temperatures fluctuating severely over the year. EnergyPlus in combination with GenOpt optimization software was used to create calibrated models that could predict temperatures in the tower throughout the year. The calibrated energy model can be used to predict the effect that possible retrofits may have on moisture-related damage such as freeze-thaw cycling and elevated moisture contents.
\end{abstract}

\section{Introduction}

The case study for this project is the Southwest Tower of the East Block building in Ottawa. Located on Parliament Hill and built between 1859-1867, the building is a unique and beautiful piece of Gothic Revival architecture and has federal heritage designation.

The buildings on Parliament Hill have been known to suffer from chronic moisture damage over their existence. This has resulted in problems such as staining, efflorescence, leaching of mortar and freeze-thaw action. With this knowledge, any proposed thermal retrofits are met with caution for concerns damage will be intensified. It is hypothesized that the interior climate can influence the hygrothermal performance of the tower. There is precedence in other tower of this building to install HVAC systems into unoccupied portions with the goal of reducing assisting drying and reducing deterioration of the masonry. This is not an energy efficient solution to problem of durability.

Before initiating a thermal retrofit of the tower, it is important to understand the behaviour in its present state. This where calibrated models are useful. A calibrated energy model can be used in conjunction with hygrothermal models to establish baseline conditions of temperatures in the tower and hygrothermal performance of the masonry. Retrofit measures can be inserted into the calibrated models and the impacts on the interior ambient conditions and hygrothermal performance can be projected.

The tower rises approximately $47 \mathrm{~m}$ tall and consists of load bearing masonry walls ranging in thickness from $860 \mathrm{~mm}$ at the top - to $2100 \mathrm{~mm}$ at the plinth. The typical wall cross-section consists of outer and inner sandstone wythes $(200-225 \mathrm{~mm})$ sandwiching a rubble core of varying thicknesses.

The two-storey lobby serves as the ground floor of the tower and is capped by a groin vault ceiling. The upper parts of the tower are unoccupied. The zones in the tower are characterized by large floor-to-ceiling heights $(\sim 12.0 \mathrm{~m}, 7.9 \mathrm{~m}$ and $7.9 \mathrm{~m}$ for the lobby, fifth and sixth floor respectively).

The upper zones of the tower do not have a dedicated HVAC system and receives heat and airflow from neighbouring pavilions. The fourth floor used to house electronic equipment, but this has recently been removed. This equipment was generating enough heat which was exhausted up the tower to control temperatures. Because of the semi-conditioned nature of the tower, the zone ambient temperatures fluctuate significantly over the course of the year and over the course of the day. This makes it difficult to accurately characterize the interior conditions by sine curves or fixed values for hygrothermal modelling.

\section{Methods}

This project has three stages, that will be presented in this paper:

1. Sensor Installation and Data Collection

2. Calibrated Energy Modelling

3. Calibration of Wall to measured intermediate temperatures and heat flux

The first stage is to install instrumentation at in the ground, fourth, fifth and sixth floors in the tower to record ambient temperature and relative humidity. This information was recorded at 15-minute intervals.

Figure 1 shows the measured and ambient temperatures from the period between September 2017 to August 2018. Of particular concern, is that the temperatures in the fifth and sixth levels dip below freezing in December, meaning the entire cross-section of the walls is subjugated to freeze-thaw cycling. This was not always the case. Figure 2 shows the measured ambient temperatures from 201213 when the heat generating electronic equipment in Zone-4 was still active (Glazer, 2013). Never was there an average daily temperature below freezing, and the temperatures in Zone-4 and Zone-5 were within a reasonably comfortable range throughout the year, never falling below $18^{\circ} \mathrm{C}$. The removal of the equipment has had a negative impact on the health of the masonry. 


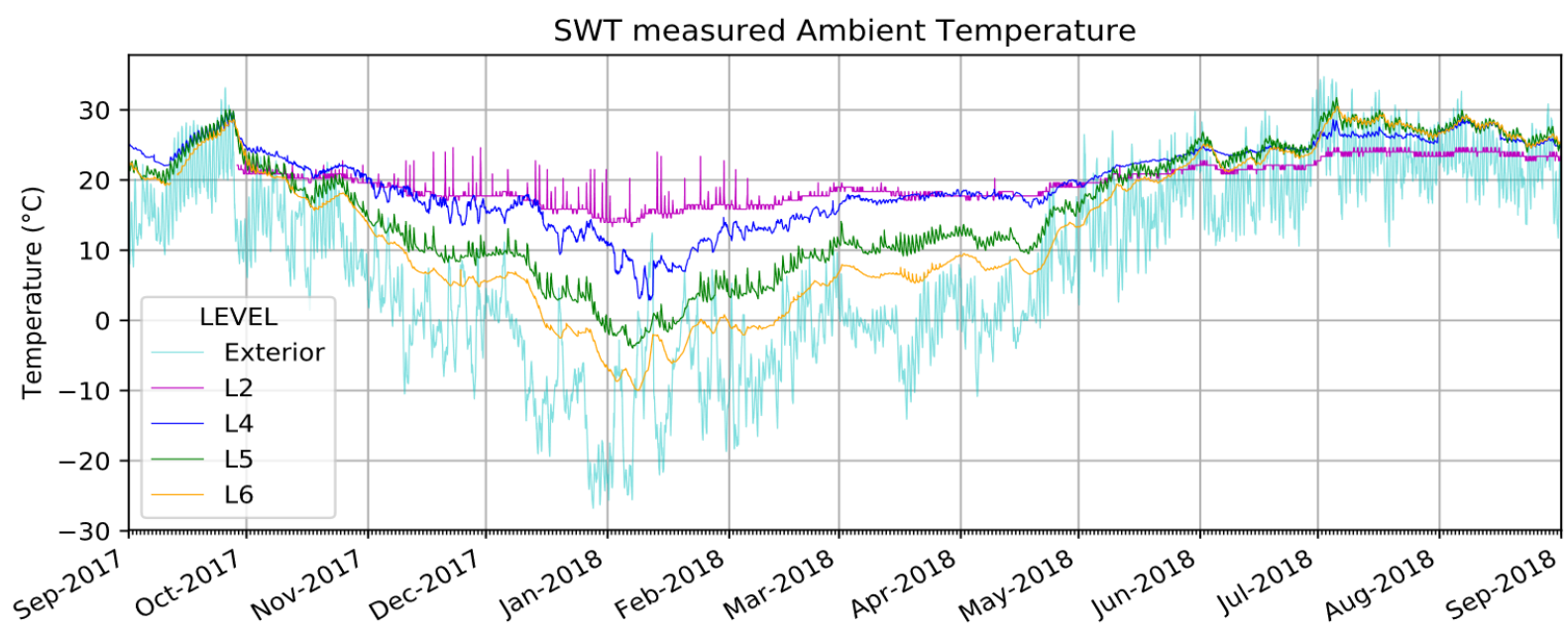

Figure 1: Measured dry-bulb temperatures inside the Southwest Tower from September 2017 to August 2018.

Of note, $\mathrm{RH}$ and wood moisture sensors were inserted into the masonry core to gauge wetting and drying patterns over the year. Briefly, we found two of the three walls monitored saw sustained $\mathrm{RH}$ at $100 \%$ and moisture content (MC) approaching saturation. This emphasizes the need to assess durability.

\section{EnergyPlus Model}

An EnergyPlus model of the Southwest Tower was created based off photogrammetric drawings and point clouds. Thermal zoning was done on a per floor basis. It is difficult to define clear-field geometry because of numerous decorative carved elements and changes in wall thicknesses. The exterior walls were sub-divided as best as possible considering model simplicity. The material composition of the wall was divided into an inner and outer wythe with rubble core (varying thickness). The material properties of sandstone and rubble core were assumed to be different. The Conduction Finite Difference algorithm was chosen for all exterior surfaces. The tower has a low window-to-wall ratio. All windows are single-pane and were simplified into equivalent rectangular shaped areas in EnergyPlus.

The tower does not have a dedicated HVAC system and receives heating, cooling and ventilation from neighbouring zones. The ground floor zone receives air circulation from large open corridor doors from adjacent wings of the building. Airflow was modelled as a constant flow rate at near room temperature. For the fourth floor, a constant volume fan exhausts air up to the fifth floor and is always operating. This was modelled as a constant Zone Mixing object in EnergyPlus. Similarly Zone Mixing objects were used to model air flow rate for the stories

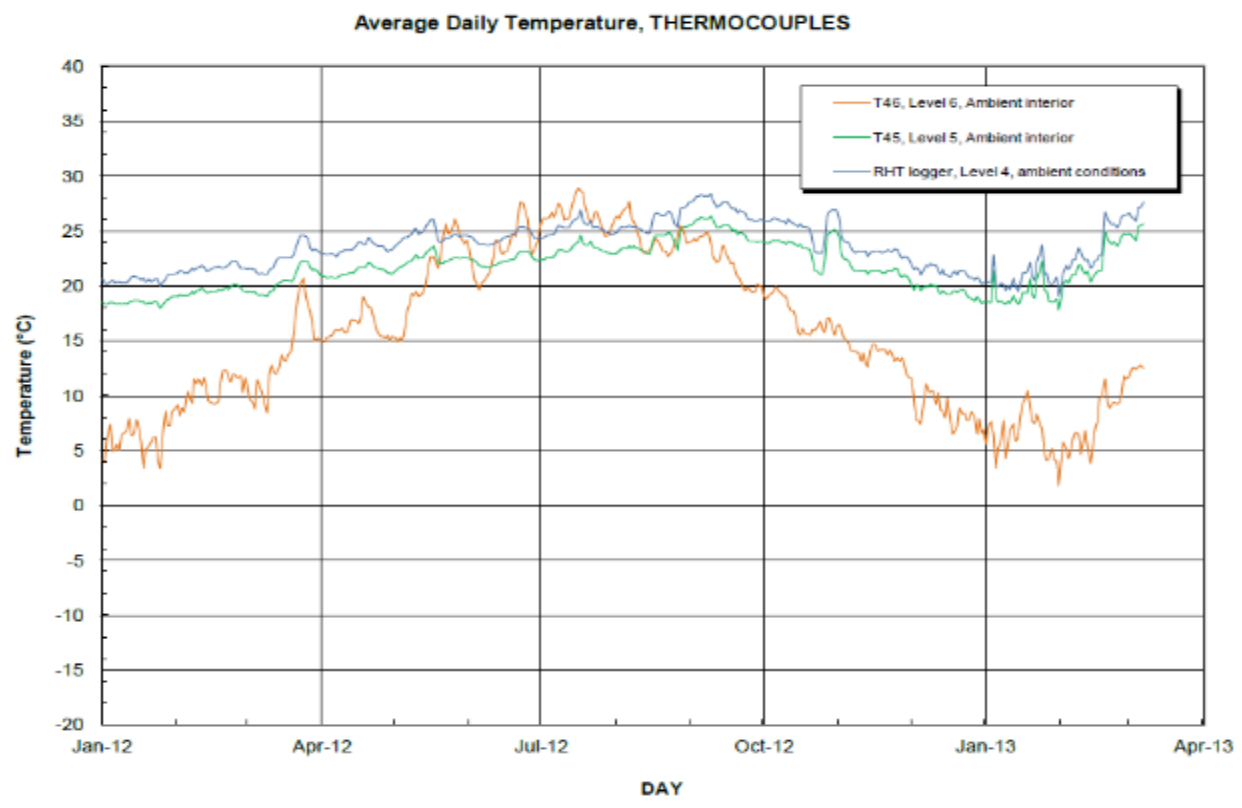

Figure 2: Measured dry-bulb temperatures inside the Southwest Tower from January 2012 to April 2013. 
above. These zone mixing objects encapsulate air movement driven by the fan and from the stack effect. Replacement air for the fourth floor comes from infiltration from the neighbouring conditioned zones and attics of the South and West pavilions. The exact source and temperature of the air is uncertain. To simplify this in the model, the replacement air was modelled as a constant flow rate at a temperature which fluctuates throughout the year.

Zone exfiltration was modelled using a unique baseline $\mathrm{ACH}$ for each floor. Temperature and air velocity coefficients based off the BLAST default model in EnergyPlus (EnergyPlus, 2017) were added to the baseline ACH. Lighting and occupancy loads are minimal.

Actual weather data was compiled into epw format from data from the Urbandale Centre for Home Energy Research (Urbandale, 2017) project on the Carleton University Campus and supplemented with data from Environment and Climate Change Canada (Environment and Climate Change Canada, 2017).

\section{Calibrated Energy Model}

The calibration process was based on a procedure developed by Roberti et al (Roberti, Oberegger, \& Gasparella, 2015) adapted for use in this project. The first step was to perform a sensitivity analysis on 28 EnergyPlus parameters followed by calibration using GenOpt optimization software (LBNL, 2016).

The sensitivity analysis was performed over the time range of 1 September 2017 to 17 December 2017 by changing one variable at a time over a predetermined range while others remain fixed. This was done to determine which parameters have the most effect and reduce computational time in the calibration phase. The Root Mean Square Error (RMSE) of the zone temperatures between the varied model's and the baseline's model was the statistical basis of the sensitivity analysis.
A summary of the sensitivity analysis results is shown in Figure 3. The largest RMSE's were for parameters related to air transfer into a zone and mixing between zones, specifically for the zone to zone mixing parameters. Exfiltration and the coefficients used to modify it have a moderate effect. Envelope thermal parameters had a surprisingly low influence. Thermal conductivity had a measurable impact, but heat capacity did not. Optical properties of windows were negligible. The 14 most significant parameters from the sensitivity analysis were carried into the calibration process. These had an RMSE greater than $0.2^{\circ} \mathrm{C}$.

The model was calibrated using GenOpt's Particle Swarm Algorithm. The cost function that was minimized was the RMSE for all 4 zones (first, fourth, fifth, sixth) with respect to measured temperatures. The most sensitive parameters such as zone mixing, were defined with finer intervals between consecutive values, while the least sensitive were defined with coarser intervals between consecutive values. The calibration period was from 1 September 2017 to 29 January 2018. This timeframe contains a broad spectrum of weather conditions including an unseasonably hot week in September and cold conditions in December and January.

\section{Results}

The results of the calibration model are shown in Figure 4. Overall, an $\mathrm{RSME}=1.162^{\circ} \mathrm{C}$ was achieved for all four measured stories. The fourth floor had the weakest correlation with an RMSE $=1.753^{\circ} \mathrm{C}$. The fifth floor $\left(\mathrm{RMSE}=1.078^{\circ} \mathrm{C}\right)$ and the sixth floor $\left(\mathrm{RMSE}=0.957^{\circ} \mathrm{C}\right)$ both have much stronger correlations. On the fourth floor, the model lacks the diurnal temperature fluctuations of the measured data. This may be caused by the temperature of the inflowing air to the fourth-floor fluctuating, whereas the model uses steady-state values. The sixth floor has the

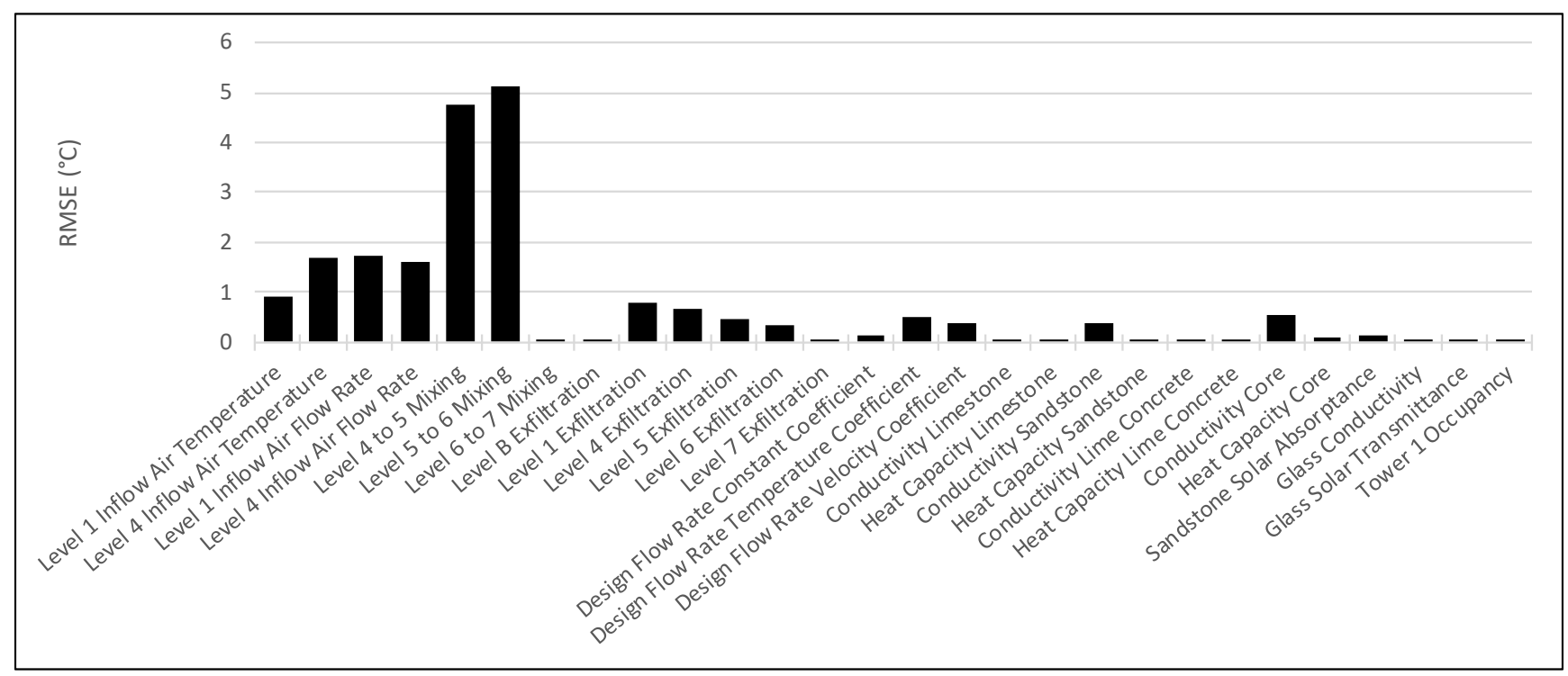

Figure 3: Sensitivity Analysis Results. 
Table 1: Final Calibration Parameters

\begin{tabular}{|c|c|c|c|c|c|c|c|c|}
\hline Parameter & \multicolumn{2}{|c|}{ Min Range } & \multicolumn{2}{|c|}{ Max Range } & \multicolumn{2}{|c|}{ Interval } & \multicolumn{2}{|c|}{$\begin{array}{l}\text { Calibration } \\
\text { Results }\end{array}$} \\
\hline Calibration & First & Second & First & Second & First & Second & First & Second \\
\hline Tower1 Inflow Air Temperature $\left({ }^{\circ} \mathrm{C}\right)$ & 18 & 20.375 & 24 & 20.875 & 0.25 & 0.125 & 20.75 & 20.75 \\
\hline Tower 4 Temperature Amplitude $\left({ }^{\circ} \mathrm{C}\right)$ & -- & 2 & -- & 5 & -- & 0.5 & - & 3 \\
\hline $\begin{array}{c}\text { Tower4 Inflow Air Temperature Maximum } \\
\left({ }^{\circ} \mathrm{C}\right)\end{array}$ & -- & 28 & -- & 31 & -- & 0.5 & -- & 29 \\
\hline $\begin{array}{l}\text { Tower4 Inflow Air Temperature Minimum } \\
\left({ }^{\circ} \mathrm{C}\right)\end{array}$ & -- & 20 & -- & 22 & -- & 0.5 & -- & 21 \\
\hline Tower1 Inflow Air Flow Rate $\left(\mathrm{m}^{3} / \mathrm{s}\right)$ & 0 & 0.375 & 1.5 & 0.5 & 0.125 & $\begin{array}{c}0.0312 \\
5\end{array}$ & 0.5 & 0.4375 \\
\hline Tower4 Inflow Air Flow Rate $\left(\mathrm{m}^{3} / \mathrm{s}\right)$ & 0 & 0.025 & 1.5 & 0.1 & 0.125 & 0.025 & 0.1 & 0.05 \\
\hline Tower 4 to 5 Mixing $\left(\mathrm{m}^{3} / \mathrm{s}\right)$ & 0 & 0.1875 & 2.5 & 0.3125 & 0.25 & $\begin{array}{c}0.0312 \\
5\end{array}$ & 0.25 & 0.25 \\
\hline Tower 5 to 6 Mixing $\left(\mathrm{m}^{3} / \mathrm{s}\right)$ & 0 & 0.125 & 2.5 & 0.250 & 0.25 & $\begin{array}{c}0.0312 \\
5\end{array}$ & 0.25 & 0.1875 \\
\hline Tower1 Exfiltration $(1 / \mathrm{h})$ & 0.1 & 0.25 & 0.9 & 0.5 & 0.1 & 0.05 & 0.4 & 0.3 \\
\hline Tower4 Exfiltration $(1 / \mathrm{h})$ & 0.1 & 0.025 & 0.9 & 0.1 & 0.1 & 0.025 & 0.1 & 0.05 \\
\hline Tower5 Exfiltration $(1 / \mathrm{h})$ & 0.1 & 0.025 & 0.9 & 0.15 & 0.1 & 0.025 & 0.15 & 0.05 \\
\hline Tower6 Exfiltration $(1 / \mathrm{h})$ & 0.1 & 0.025 & 0.9 & 0.1 & 0.1 & 0.05 & 0.15 & 0.05 \\
\hline $\begin{array}{l}\text { Design Flow Rate Temperature Coefficient } \\
(--)\end{array}$ & 0 & 0 & 0.075 & 0.01 & $\begin{array}{c}0.0187 \\
5\end{array}$ & 0.005 & 0 & 0 \\
\hline Design Flow Rate Velocity Coefficient (--) & 0 & 0 & 0.25 & 0.03 & 0.0625 & 0.01 & 0 & 0 \\
\hline Conductivity Sandstone (W/m-K) & 1.0 & 1.5 & 4 & 2.25 & 0.25 & 0.25 & 1.5 & 2 \\
\hline Conductivity Core (W/m-K) & 1.0 & 2.0 & 4 & 2.5 & 0.25 & 0.125 & 2.75 & 2.25 \\
\hline
\end{tabular}

opposite problem where the model predicts diurnal fluctuations whereas the measured data does not. Generally, the RMSE is higher during cold periods than warm.
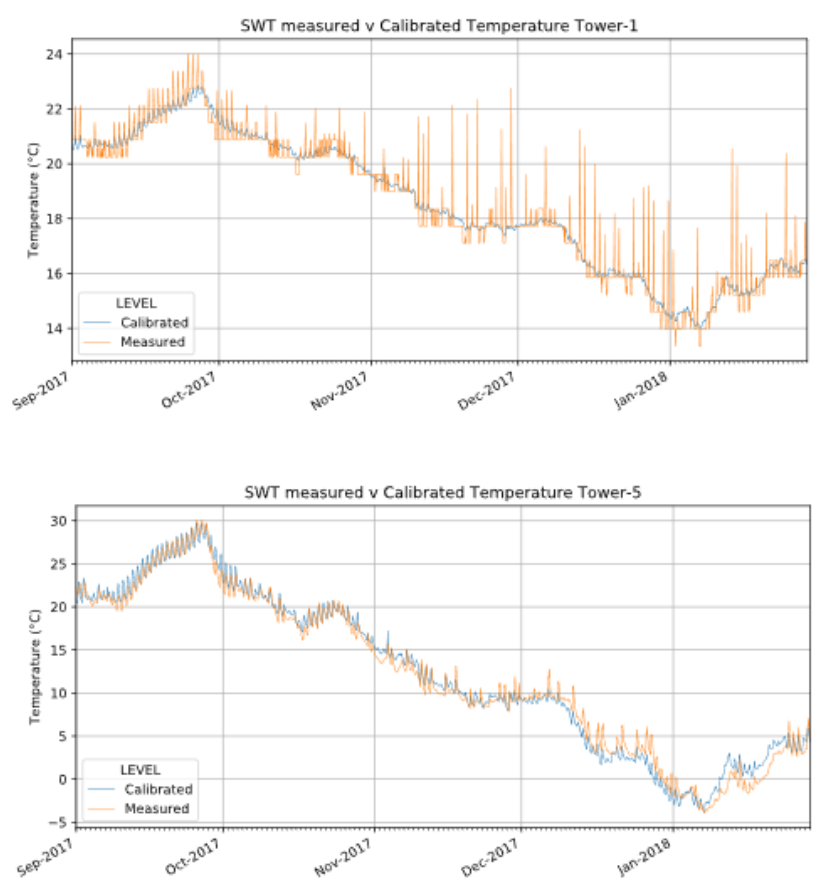

\section{Discussion}

The results of the calibrated model were satisfactory and comparable to other studies performed on heritage buildings where interior ambient temperatures were the
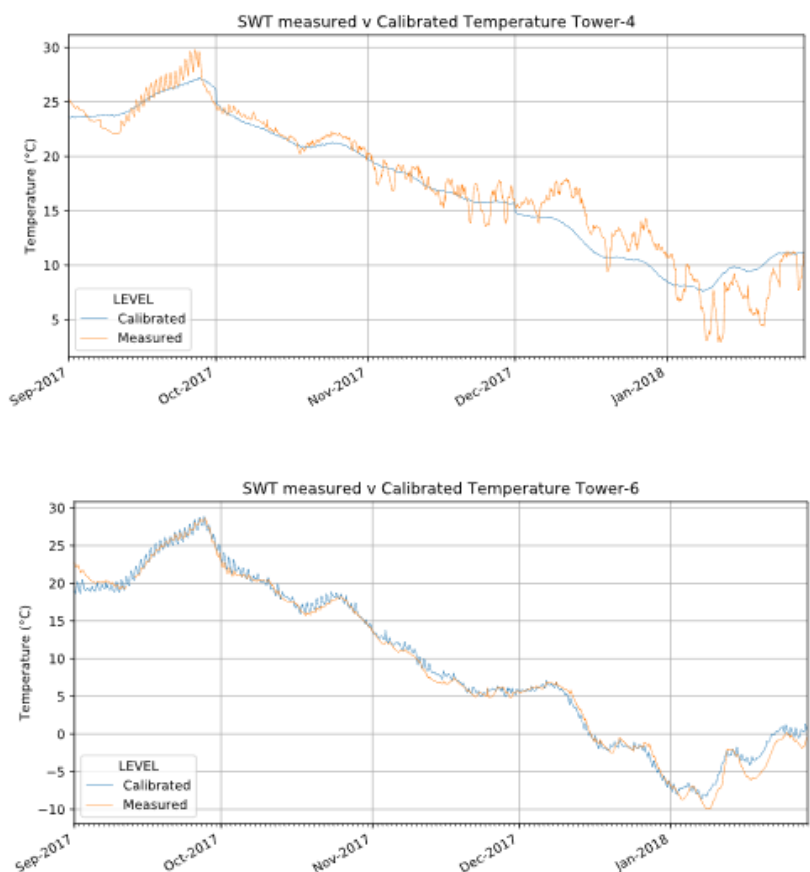

Figure 4: Calibrated v. Measured data for the first calibrated model 


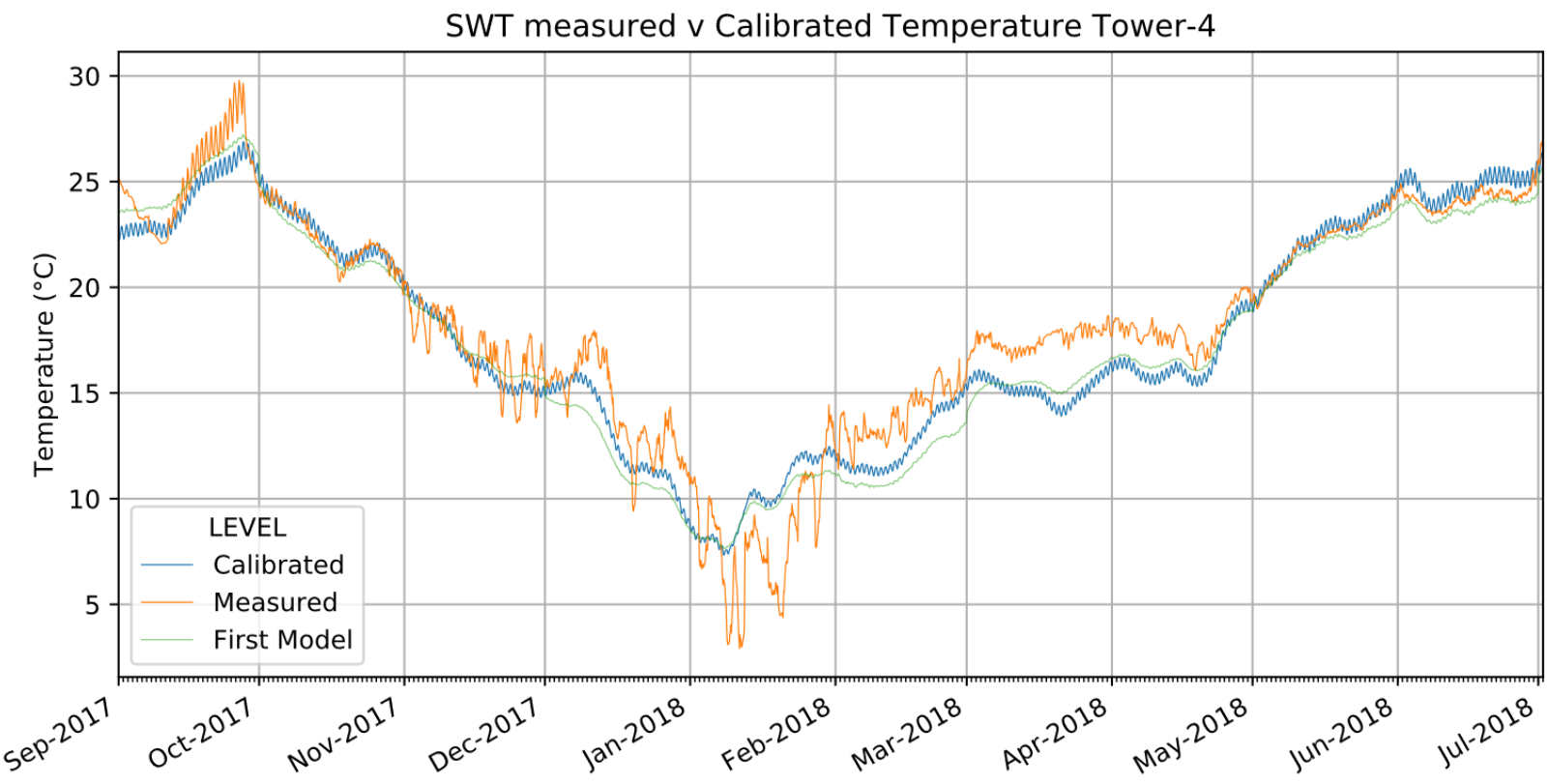

Figure 5: Time graph for the fourth-floor after the second calibration period with projected results of the first model.

calibration target (Pernetti, Prada, \& Baggio, 2013; Roberti et al., 2015). Despite this, there are several opportunities to improve the model; and the model's ability to predict the future still needs to be verified. A second calibrated model was done to address both issues.

Changes to the calibration model included an extension of 6 months to 2 August, a function was created to vary the temperature of the incoming air into the fourth floor based on exterior climate and a tighter range of values and intervals for parameters was used. A summary of the calibration parameters, their ranges and final results are presented in Table 1.

The results of the second calibrated model are presented in Figure 5 (fourth-floor only). The overall RMSE for this model was reduced to $1.040^{\circ} \mathrm{C}(-10.5 \%)$. The RMSEs for the second half of the calibration period were generally better than the first half. There are some periods that the model still cannot adequately explain. In late winter and early spring, there is a difference of around $3-5^{\circ} \mathrm{C}$ on the fourth floor. The calibrated added some of the diurnal effect to the fourth floor which was absent from the first model.

The fourth floor during the heating season is still the weak point of the model. This discrepancy may be caused by changes in building operation, unidentified heat source or change in stack effect.

The calibrated energy model is evolutionary. As more data comes in, it gives more opportunity to verify its accuracy, identify patterns where the model is weak and to update the model accordingly.

\section{Wall Calibration}

The theme of calibration was extended to analysis of individual walls by comparing measured heat flux, surface temperatures and interstitial temperatures. This will help to verify some of the wall's thermal properties from the EnergyPlus calibration.

Two wall sections were studied; the fourth-floor south façade and the sixth-floor south façade. Both walls had Type T thermocouples and Omega HSF-4 Thin Film Heat Flux Sensors (OMEGA Engineering, n.d.) affixed to the interior surface (the sixth floor heat flux sensor debonded from the wall midway through the experiment and its results are not discussed further). Interstitial temperatures were recorded via Vaisala RH Sensors (Vaisala, 2011) on the sixth floor and by SMT Embedded Moisture Sensors (EMS) on the fourth floor (SMT Research, n.d.). These sensors were installed to monitor hygrothermal conditions over time and were staggered at different depths. The heat flux sensors have an uncertainty of $\pm 10 \% \mathrm{~W} / \mathrm{m}^{2}$ and the Type $\mathrm{T}$ thermocouples have an uncertainty of $\pm 0.5^{\circ} \mathrm{C}$.

Two types of calibration metrics were used. The first was to perform a calibration based on measured temperatures. The second was to calibrate against measured heat flux.

DELPHIN 6.0 was chosen to for the calibration of the wall because of the flexibility it offers with regard to temperature and moisture-dependent conduction and has two-dimensional capabilities (Bauklimatik Dresden, 2018).

The model was a simple two-dimensional wall shown in Figure 6. The model was separated into two material types

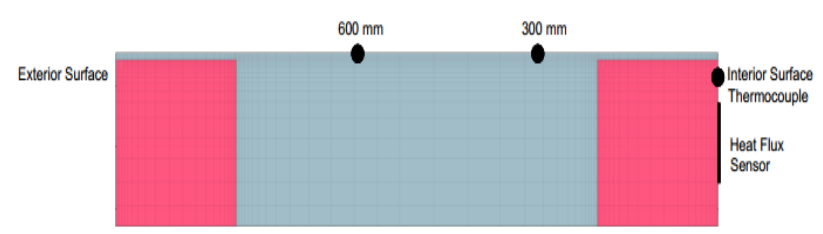

Figure 6: DELPHIN 6.0 model used for calibration of wall thermal properties. 
Table 2: Parameters for wall calibration

\begin{tabular}{|c|c|c|c|c|c|}
\hline \multirow{2}{*}{ Parameter } & \multicolumn{2}{|c|}{ Range } & Interval & \multicolumn{2}{c|}{ Calibration Results } \\
\cline { 2 - 6 } & Min & Max & & Temperature $\left(6^{\text {th }}\right.$ floor $)$ & Heat Flux $\left(4^{\text {th }}\right.$ floor $)$ \\
\hline Conductivity Sandstone $(\mathrm{W} / \mathrm{m}-\mathrm{K})$ & 1.0 & 2.5 & 0.25 & 1.0 & 2.0 \\
\hline Conductivity Core $(\mathrm{W} / \mathrm{m}-\mathrm{K})$ & 0.7 & 1.1 & 0.10 & 0.7 & 1.1 \\
\hline Capacity Sandstone $(\mathrm{J} / \mathrm{kg}-\mathrm{K})$ & 550 & 1150 & 100 & 550 & 550 \\
\hline Capacity Core $(\mathrm{J} / \mathrm{kg}-\mathrm{K})$ & 550 & 1150 & 100 & 1050 & 6 \\
\hline Interior Convection Coefficient $\left(\mathrm{W} / \mathrm{m}^{2}-\mathrm{K}\right)$ & 6 & 10 & 1 & 10 & 4 \\
\hline Exterior Convection Coefficient $\left(\mathrm{W} / \mathrm{m}^{2}-\mathrm{K}\right) *$ & 4 & 8 & 1 & 8 & 0.9 \\
\hline Solar Absorption Coefficient $(--)$ & 0.5 & 0.9 & 0.1 & 0.9 & 150 \\
\hline *Note that the values here are the variahle $x$ in Fouation 1
\end{tabular}

(Sandstone and Mortar/Core). The two materials were thought to have different thermal properties, especially the sandstone having a much higher conductivity than the mortar/core.

DELPHIN allows for exterior convection coefficients to vary linearly based on wind velocity. A correlation based on Nusselt and Jurges (1922) was used but with a variable constant term $(x)$ to go with the fixed linear term (EnergyPlus, 2017).

Equation 1

$$
h_{e}=x+3.94 V_{z}
$$

Where $\mathrm{h}_{\mathrm{e}}=$ exterior convection coefficient $\left[\mathrm{W} / \mathrm{m}^{2}-\mathrm{K}\right], \mathrm{x}$ is a variable constant, and $\mathrm{V}_{\mathrm{z}}=$ local wind speed $[\mathrm{m} / \mathrm{s}]$.

Interior convection was specified at a fixed value. DELPHIN does not have an adaptive algorithm for interior convection like EnergyPlus does. However, it is expected this value remains relatively stable.

Because conductivity is a function of moisture-content in porous media the fraction of absorbing rain and initial $\mathrm{RH}$ was modified depending on which wall was being simulated. modified depending on which wall was being simulated. The $4^{\text {th }}$ floor walls were giving higher values to represent its known moisture issued (and theoretically higher conductivity). The default moisture and temperature dependent formulas was used (Vogelsang, Fechner, \& Nicolai, 2018). A list of the input parameters is shown in Table 2.

The calibration was again performed with GenOpt using the Particle Swarm Algorithm. The timeframe began on 15 September and lasted for 270 days ( 9 months) for the sixth floor. It began on 1 February and lasted for 180 days (6 months) on the fourth floor.

\section{Calibration against measured temperatures}

The results for the calibrated model of the $6^{\text {th }}$ floor are summarized in Figure 7. In general, the RMSE for each sentinel are better toward the interior than the exterior. The RMSE for the surface temperature have a good correlation to measured values.

The calibrated model of the $6^{\text {th }}$ floor lead to some surprising and noteworthy results: The results of the calibration pointed toward the thermal conductivity of the sandstone being much lower than initially thought $(<1.0$ $\mathrm{W} / \mathrm{m}^{2}-\mathrm{K}$ ). This could have been influenced by the presence of voids acting as insulating layers. This result needs to be inferred as an effective conductivity averaged throughout the layer and not as an inherent material property.

The second surprising outcome was that the interior convection coefficient was at the high end of the anticipated range $\left(>10 \mathrm{~W} / \mathrm{m}^{2}-\mathrm{K}\right)$. This indicates one of 2 things. First there is sufficient air movement in the tower either through buoyant or force convective loops); or that there is a small measurement bias in the surface mounted thermocouple that infers higher convection coefficients.

The next noticeable result was that the calibrated model tended toward unusually high solar absorption coefficients $(\alpha>0.9)$. Coefficients this high are typical of black coloured materials. The masonry has endured
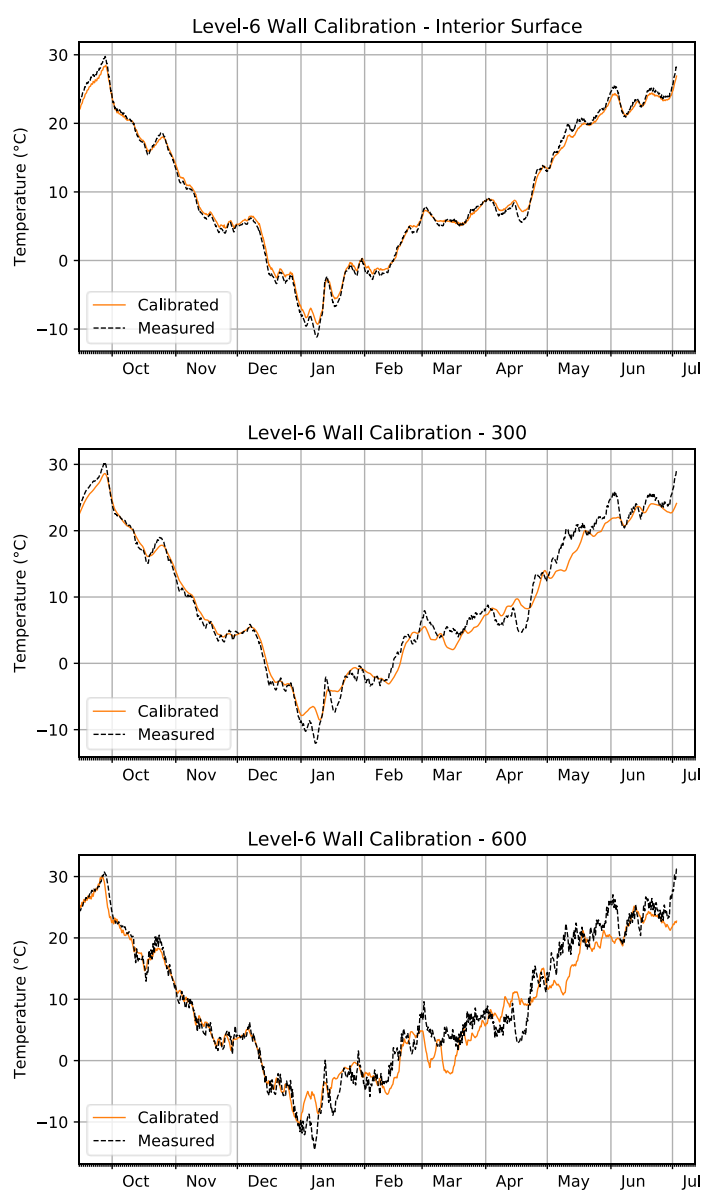

Figure 7: Calibrated v. Measured data for the wall temperature calibration along the interior surface, $300 \mathrm{~mm}$ and $600 \mathrm{~mm}$ depths. 
Table 3: Wall Calibration results

\begin{tabular}{|c|c|c|}
\hline Model & Sentinel & RMSE \\
\hline $\begin{array}{c}\text { Temperature (6th } \\
\text { floor) }\end{array}$ & Overall & $1.928^{\circ} \mathrm{C}$ \\
\cline { 2 - 3 } & Interior surface & $0.678^{\circ} \mathrm{C}$ \\
\cline { 2 - 3 } & $\begin{array}{c}300 \mathrm{~mm} \text { from } \\
\text { interior }\end{array}$ & $1.656^{\circ} \mathrm{C}$ \\
\cline { 2 - 3 } & $\begin{array}{c}600 \mathrm{~mm} \text { from } \\
\text { interior }\end{array}$ & $2.818^{\circ} \mathrm{C}$ \\
\hline Heat Flux (4th floor) & Interior surface & $5.150 \mathrm{~W} / \mathrm{m} 2$ \\
\hline
\end{tabular}

significant soiling which has turned the stone a much darker colour.

The results were much better for the first 3 months than the rest of the calibration period. After this there are several anomalies which are not easily explained. In general, the temperatures are underestimated in the calibrated model.

The calibration to the interior surface is good, but as we move toward the exterior, the RMSEs get progressively worse (Table 3 ). Because the interior boundary condition was had a good correlation, the fact that the correlation of the model decays as we go toward the exterior indicates an uncertainty with the exterior boundary condition, either with the weather file, solar absorption coefficients or exterior convection coefficients.

\section{Calibration against measured heat flux}

The results for the calibrated model of the $6^{\text {th }}$ floor are summarized in Figure 8. Positive heat flux is energy flowing out of the zone and negative is heat flowing toward the interior on warm days. An RMSE of 5.150 $\mathrm{W} / \mathrm{m}^{2}$ was achieved for the 6-month time period. There are some noticeable weak points in the model, where there is poor correlation. In February when heat transfer is near its peak, there is a consistent difference of approximately $5 \mathrm{~W} / \mathrm{m}^{2}$. This is echoed from the calibration of the tower where it was difficult to model in winter. There is a strong anomaly in April and in July there is a large discrepancy where the sensor is reading significant heat gain into the space, whereas the model never registers significant heat gain into the space.

While the calibrated model was not always able to achieve comparable magnitudes throughout, the amplitude of the diurnal amplitude was well represented. For example, in early February and in July, where there were prominent oscillations in the measured heat flux and the model was able to replicate this. Similarly, in May where there are relatively stable diurnal effects, the model is able to replicate this. The results returned an effective U-value of $1.38 \mathrm{~W} / \mathrm{m}^{2}-\mathrm{K}$. This comparable to previous in-situ studies of historic masonry by Lucchi (2017) and Baker (2011), with consideration that this wall is much thicker, has a very dense sandstone and is at a critical level of saturation. The heat flux calibration returned both similar and contradictory findings to the wall temperature calibration. This model shared a tendency toward very high solar absorptivity and lower heat capacities. This indicates the wall has much more thermal dynamism than expected. The two factors lead to the fact there may be less thermal mass in the wall and that the numerous voids in the wall may be a contributor. This can also explain why we do not see the measured minimum and maximum heat fluxes as shown in Figure 8. The high solar absorptance may be attributed to the knuckled texture of the stone which gives more surface area than a flat planar surface.

The calibrated heat flux model does not share the calibrated wall temperature model's trend toward low thermal conductivity. Part of the difference between the two may be attributed to the $4^{\text {th }}$ floor wall being saturated and the $6^{\text {th }}$ floor being dry. The thermal conductivity for

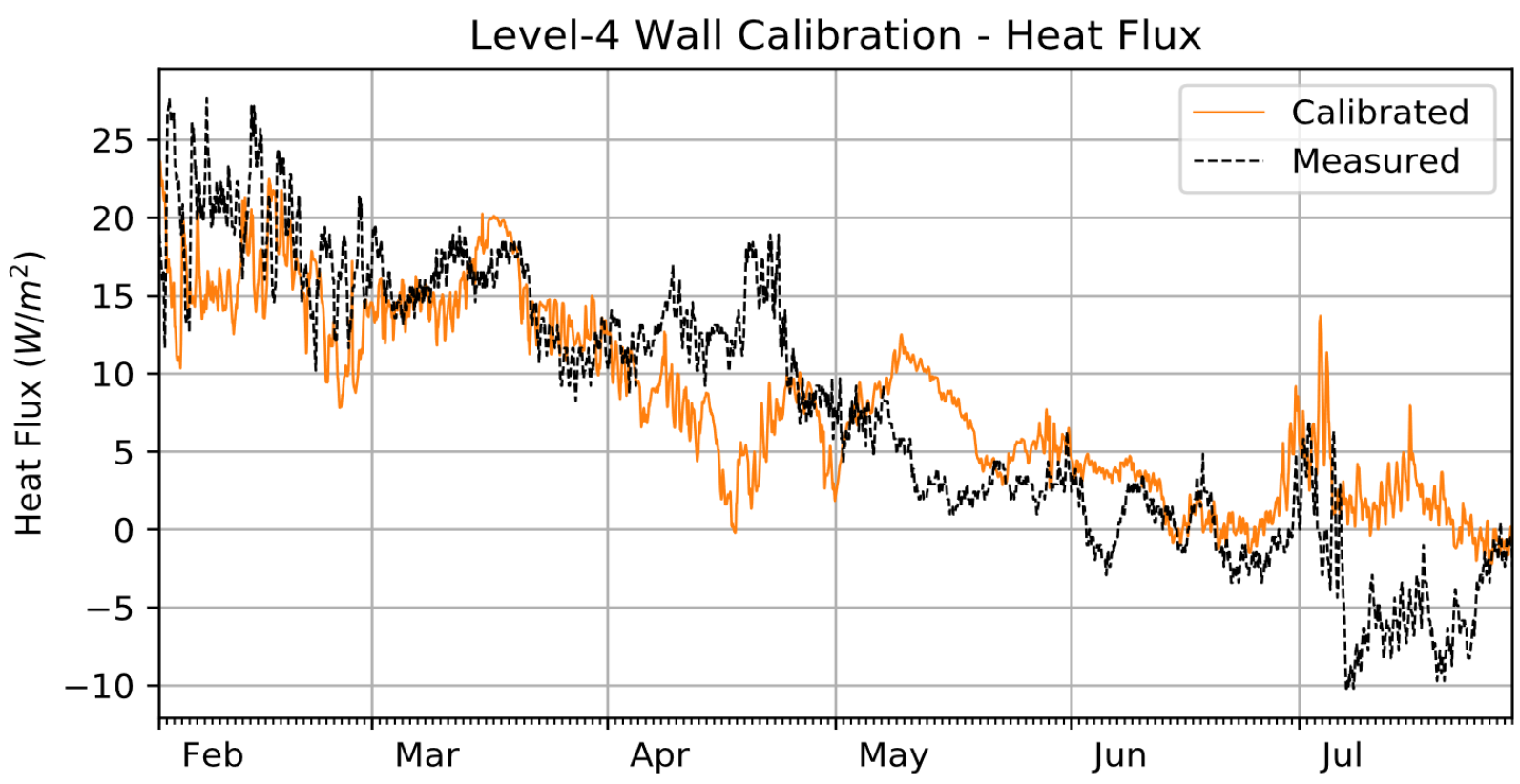

Figure 8: Measured v. Calibrated surface heat flux for the fourth-floor South facade. 
sandstone is more representative of what was found in the EnergyPlus calibration of the whole tower. The heat flux calibration returned interior convection coefficients that were much lower.

Between the two methods presented here for calibrating a wall, the heat flux method appears more trustworthy. It returns parameter values which are more plausible, especially for thermal conductivity. The fact that the wall studied is essentially symmetrical and the relatively similar conductivity between materials makes it difficult to ascertain conductivity. The interstitial temperature profile is essentially linear between the exterior and interior surface temperatures, no matter what value is selected for conductivity. This also gives too much weight to both the interior and exterior coefficients.

\section{Conclusion}

Calibrated energy models of the Southwest Tower of the East Block building were performed against ambient air temperatures and surface heat flux measurements beginning in September 2017. Two types of calibrated model were developed; an EnergyPlus model of the entire tower and two-dimensional finite element models of a corresponding masonry wall assembly. The goal of this process is to both characterize the building's performance in its current state and to help define the thermal properties of the mass masonry walls in-situ.

An EnergyPlus model of the tower was created and the model was calibrated using GenOpt. The calibrated model for the entire tower achieved an RMSE of $1.040^{\circ} \mathrm{C}$ for the period between 1 September to 2 August across all 4 measured zones. Modelling parameters which had the greatest influence on the model were those regarding air transfer and mixing between zones. Air infiltration, and thermal properties of the masonry envelope had a moderate influence, while glazing and optical properties had negligible impact.

Calibrated models of wall assemblies were developed using DELPHIN 6.0. Interstitial temperatures and interior surface heat flux were used as metrics for the calibration.

An overall RMSE of $1.928{ }^{\circ} \mathrm{C}$ was achieved for the sixthfloor wall using temperatures. A good RMSE was achieved for interior surface temperatures, but the quality of the calibration as you progress towards the exterior. An RMSE of $5.150 \mathrm{~W} / \mathrm{m}^{2}$ was achieved for the fourth-floor wall using measured heat flux to calibrate against. The parameters from these models trended toward higher solar absorption and lower heat capacities than default assumptions. This leads to assume that the wall has a more dynamic thermal response. Between the two methods of calibrating the wall, the heat flux sensor was deemed more reliable.

\section{Acknowledgements}

Thank you to Public Works and Government Services Canada - Heritage Conservation Services and
Parliamentary Precinct Branch and RDH Building Sciences Inc. for their help on this project.

\section{References}

Baker, P. (2011). U-values and traditional buildings - In situ measurements and their comparisons to calculated values (No. Technical Paper 10). Edinburgh: Historic Scotland.

Bauklimatik Dresden. (2018). DELPHIN 6.0 (Version 6.0.18).

EnergyPlus Version 8-8-0 Documentation - Engineering Reference. (2017, September 26). U.S. Department of Energy.

GenOpt - Generic Optimization Program (Version 3.1.1). (2016). Lawrence Berkeley National Laboratory.

Glazer, R. (2013). Hygrothermal Monitoring of Southwest Tower, East Block, Parliament Hill (No. A1-00261302.1). National Research Council.

Historical Data. (2017). Retrieved from http://climate.weather.gc.ca/historical_data/search_hi storic_data_e.html

Lucchi, E. (2017). Thermal transmittance of historical stone masonries: A comparison among standard, calculated and measured data. Energy and Buildings, 151 , 393-405. https://doi.org/10.1016/j.enbuild.2017.07.002

OMEGA Engineering. (n.d.). Thin-Film Heat Flux Sensors. OMEGA Engineering.

Pernetti, R., Prada, A., \& Baggio, P. (2013). On the influence of several parameters in energy model calibration: the case of a historical building. Conference: 1st IBPSA Italy Conference, 10.

Roberti, F., Oberegger, U. F., \& Gasparella, A. (2015). Calibrating historic building energy models to hourly indoor air and surface temperatures: Methodology and case study. Energy and Buildings, 108, 236-243. https://doi.org/10.1016/j.enbuild.2015.09.010

SMT Research. (n.d.). Embedded Moisture sensor Product Datasheet. Structural Monitoring Technology.

Urbandale Centre for Home Energy Research. (2017). Carleton University.

Vaisala. (2011). Vaisala INTERCAP® Humidity and Temperature Probe HMP60 Technical Data. Vaisala.

Vogelsang, S., Fechner, H., \& Nicolai, A. (2018). Delphin 6 Material File Specification, Version 6.0. Institut für Bauklimatik. 